\title{
Transferability of the EST-SSRs developed on Nules clementine (Citrus clementina Hort ex Tan) to other Citrus species and their effectiveness for genetic mapping
}

\author{
François L Luro*1, Gilles Costantino1, Javier Terol2 ${ }^{2}$, Xavier Argout ${ }^{3}$, \\ Thierry Allario ${ }^{4}$, Patrick Wincker ${ }^{5}$, Manuel Talon ${ }^{3}$, Patrick Ollitrault ${ }^{4}$ and \\ Raphael Morillon ${ }^{4}$
}

\begin{abstract}
Address: ${ }^{1}$ INRA, Unité de Recherche GEQA, INRA San Giuliano, 20230 San Nicolao, France, ${ }^{2}$ Centro de Genomica, Instituto Valenciano de Investigationes Agrarias, Valencia, Spain, ${ }^{3}$ CIRAD AMIS, Montpellier, France, ${ }^{4}$ UPR 'Amélioration génétique d'espèces à multiplication végétative', CIRAD, Montpellier, France and ${ }^{5}$ Genoscope, CNS, Evry, France

Email: François L Luro* - luro@corse.inra.fr; Gilles Costantino - costantino@corse.inra.fr; Javier Terol - jterol@ivia.es;

Xavier Argout - argout@cirad.fr; Thierry Allario - allario@cirad.fr; Patrick Wincker - pwincker@genoscope.cns.fr;

Manuel Talon - mtalon@ivia.es; Patrick Ollitrault - ollitrault@cirad.fr; Raphael Morillon - morillon@cirad.fr

* Corresponding author
\end{abstract}

Published: 16 June 2008

BMC Genomics 2008, 9:287 doi:10.1186/147|-2164-9-287

This article is available from: http://www.biomedcentral.com/147I-2164/9/287

(c) 2008 Luro et al; licensee BioMed Central Ltd.

This is an Open Access article distributed under the terms of the Creative Commons Attribution License (http://creativecommons.org/licenses/by/2.0), which permits unrestricted use, distribution, and reproduction in any medium, provided the original work is properly cited.
Received: 13 January 2008

Accepted: 16 June 2008

\begin{abstract}
Background: During the last decade, numerous microsatellite markers were developed for genotyping and to identify closely related plant genotypes. In citrus, previously developed microsatellite markers were arisen from genomic libraries and more often located in non coding DNA sequences. To optimize the use of these EST-SSRs as genetic markers in genome mapping programs and citrus systematic analysis, we have investigated their polymorphism related to the type (di or trinucleotide) or their position in the coding sequences.
\end{abstract}

Results: Among I 1000 unigenes from a Clementine EST library, we have found at least one microsatellite sequence (repeated units size ranged from 2 to 6 nucleotides) in 1500 unigenes (13.6\%). More than $95 \%$ of these SSRs were di or trinucleotides. If trinucleotide microsatellites were encountered trough all part of EST sequences, dinucleotide microsatellites were preferentially (50\%) concentrated in the 5' 100th nucleotides. We assessed the polymorphism of $4 \mathrm{I}$ EST-SSR, by PCR amplification droved with flanking primers among ten Citrus species plus 3 from other genera. More than $90 \%$ of EST-SSR markers were polymorphic. Furthermore, dinucleotide microsatellite markers were more polymorphic than trinucleotide ones, probably related to their distribution that was more often located in the $5^{\prime}$ UnTranslated Region (UTR). We obtained a good agreement of diversity relationships between the citrus species and relatives assessed with EST-SSR markers with the established taxonomy and phylogeny. To end, the heterozygosity of each genotype and all dual combinations were studied to evaluate the percentage of mappable markers. Higher values ( $>$ 45\%) were observed for putative Citrus inter-specific hybrids (lime lemon, or sour orange) than for Citrus basic true species (mandarin, pummelo and citron) (<30\%). Most favorable combinations for genome mapping were observed in those involving interspecific hybrid genotypes. Those gave higher levels of mappable markers (>70\%) with a significant proportion suitable for synteny analysis.

Conclusion: Fourty one new EST-SSR markers were produced and were available for citrus genetic studies. Whatever the position of the SSR in the ESTs the EST-SSR markers we developed are powerful to investigate genetic diversity and genome mapping in citrus. 


\section{Background}

Simple Sequence Repeats are tandem repeat sequences that are quite abundant in eukaryotes genomes [1]. Numerous genomic libraries enriched in SSR have been established from many plant species [2-5]. Those repeat sequences also called microsatellites (MS) present a higher level of polymorphism and higher expected heterozygosity when compared with to other dominant (AFLP and RAPD) or codominant markers (RFLP) [6]. Since SSRs are ubiquitously present in genomes with randomly occurrence, they are communally used as genetic markers in many different plant species to unravel the interspecific and intraspecific diversity [7-10].

In citrus, the number of published markers of genomic SSRs is still limited $[11,12]$. Those markers were used for genetic diversity assessment and for germplasm management $[13,14]$. A high-density microsatellite consensus map is still lacking. The major goal of genetic mapping is to localize genes or QTLs, involved in traits of interest that are linked to molecular markers. Those molecular markers can be used as a starting point for gene identification or to reduce schemes of selection. One other way to address this aim is to develop markers directly localized in the coding sequences. ESTs (Expressed Sequence Tags) derived from cDNA libraries obtained from the genome expression have been investigated for microsatellite screening, in barley [15], wheat [16], rice [17], citrus $[18,19]$, sugarcane [20] and grape [21]. It is assumed that those SSRs markers should enable to assess the molecular evolution of the genes in which they are positioned. Indeed, it has been observed that in ESTs, the flanking region of SSRs are more conserved and can also be found in related genera [22]. Thousands of EST-SSRs were identified in numerous species such as grape and cereal. A high level of transferability was noted between rice, wheat and barley [17]. In citrus, thousands of ESTs are now available in databases. Recently, using public sequence databases resources, Chen et al. [23], published the characterization of 56 EST-SSR markers identified among 2295 citrus ESTs, mappable in a progeny obtained from a cross between sweet orange (Citrus sinensis L. Osb.) and trifoliate orange (Poncirus trifoliata L. Raf.). If those two genotypes represent important resources of agronomical characters for rootstock and cultivar improvement scheme, numerous other citrus species offer a large panel of specific traits interesting breeders or consumers. For example, Clementine (Citrus clementina Hort. Ex Tan.) is a model citrus crop in Mediterranean area and sour orange (C. aurantium L.) or Cleopatra mandarin (C. reshni Hort. Ex Tan.) are tolerant to abiotic constraints such as salt stress or calcareous soils [24]. Citrus as many fruit trees have a juvenility period with around 5 years of duration limiting the possibility to study the allelic segregation on a second generation of hybrids (F2 or BC). Consequently citrus genetic maps are established on F1 progenies at interspecific [25], and intergeneric levels [26-31]. To maximize the potential for the development of EST-SSR based maps we need to investigate the polymorphism and the heterozygosity of these markers in different combined genotypes at the origin of F1 progenies. Another point of reflexion concerning the polymorphism of SSRs in EST is the usefulness of the derived markers such as STMS (Sequence Tagged MicroSatellite) in cultivar distinctness and in relationships between varieties and species. The particular position of these SSRs inside coding sequences may question the genetic diversity information that we can extract from those markers related to the putative influence of the selection on the SSR polymorphism.

In a full-length clementine (Citrus clementina) ESTs database [19], we looked for SSR markers. Screening of 37000 ESTs allowed us to identify about 1600 SSRs. We report here the outline investigation of the polymorphism of EST-SSR among a set of 16 citrus species covering a wide range of citrus genetic diversity. We assessed also the mappability of these markers on our different progenies established for heredity studies. The effect of repeated motif length (dinucleotide or trinucleotide) and their position on the cDNA sequence, on their polymorphism are also discussed.

\section{Methods \\ SSR detection}

SSR detection was undertaken on 11632 non-redundant sequences generated by the StackPACK application homepage [32] from 37000 ESTs obtained from Nules clementine. The MIcrosAtellite identification tool (MISA) [33] was used to perform the search of 2 to 6 nucleotide motif repeats into the unigene dataset. Dinucleotide SSRs were identified with a minimum of six repeats and the other types of SSR with a minimum of five repeats. The maximum interruption between 2 SSRs to consider a SSR as a compound one was set at 100 nucleotides. Perl script modules linked to the primer modelling software Primer3 [34], were used to design primers flanking each SSR region found. The primer product size range was chosen between 100 and 280 nucleotides. The optimum size of primers was set to 17 nucleotides (range from 15 to 23 nucleotides) with an optimum melting temperature of $56.0^{\circ} \mathrm{C}$ (range from 50 to $63^{\circ} \mathrm{C}$ ). When possible, 3 pairs of primers were picked for each STMS. The localization of SSRs in comparison with the coding sequence was estimated by BLASTx analysis realised during initiation of the Clementine EST Database (ESTtik, CIRAD, Montpellier, France) for assessing putative function to the unigene sequence. The codon sequences were translated in nucleotide sequences and then the SSR position related to the CDS was elucidate and detailed as following: in 5'UTR, in CDS or in 3'UTR. 


\section{Plant material}

Sixteen citrus genotypes were investigated for microsatellite screening. Thirteen varieties from 10 species were chosen to represent the Citrus genus (Table 1). One accession of the two other true citrus genera, Fortunella marumi and Poncirus trifoliate and a related wild genus, Severinia buxifolia, completed the citrus sample set. All those accessions are maintained in the INRA CIRAD citrus depository at San Giuliano (Corsica, France).

\section{EST functional annotation}

Functional annotation of ESTs was based on Gene Ontology (GO) annotation [35], and performed of with BLAST2GO [36]. B2G parameters were: NCBI non-redundant DB for BLAST search, 20 hits maximum for BLAST result, $100 \mathrm{nt}$ as minimum HSP-length to retain putative annotating hits and default Evidence Code Weights for Gene Ontology annotation that assigns high ECWs to experimental-based and curate annotations while penalized electronic and non-curate annotations. Minimum values for BLAST e-value and \% similarity of the BLAST result were e-06 and 55\% respectively and ultimate annotation cut-off value was set to 55 .

To provide a broad representation of the distribution of gene product functions, the ESTs were organized in sets according to broad GO ontology categories, as described by the GO Slim Classification for Plants developed at TAIR. GOSlim annotations of the Citrus ESTs were also generated with the $\mathrm{B} 2 \mathrm{G}$ software, using the plant GOSlim mapping tool provided in TAIR. The GO Slim classification was performed for both the whole collection of 37 000 ESTs and the subset of sequences carrying SSRs.

\section{SSR polymorphism analysis}

Total DNA was extracted from leaf samples according to the method developed by Doyle and Doyle [37]. Amplifications were performed according to Kijas et al. [11] in a thermocycler (PTC 200, MJ Research) using $10 \mathrm{ng}$ of DNA, $0.5 \mu \mathrm{M}$ of each primer and 0.8 unit of Taq polymerase (Goldstar, Eurogentec). The annealing temperature was fixed for all primer pairs at $55^{\circ} \mathrm{C}$ (this condition was taking account during the primer designing). Separation of alleles was performed on a $6 \%$ polyacrylamide sequencing gel containing $7 \mathrm{M}$ urea in $0.5 \times$ TBE buffer at $60 \mathrm{~W}$ for $2 \mathrm{~h}$ to $3 \mathrm{~h}$. Three microliters of PCR product was mixed to an equal volume of loading buffer containing 95\% formamide, $0.25 \%$ bromophenol blue and $0.25 \%$ xylen cyanol, and $10 \mathrm{mM}$ of EDTA. This mixture was heated for $5 \mathrm{~min}$ at $94^{\circ} \mathrm{C}$ to denature the DNA before loading. Gels were stained with silver nitrate following the protocol detailed by Chalhoub et al. [38], for gel electrophoresis analysis and by comparison with the 10 bp DNA standard ladder (Invitrogen).

\section{Genetic diversity and data analysis}

Four parameters of diversity were estimated for each locus corresponding to a subset of 39 SSR markers: percentage of polymorphic loci, the mean number of alleles per locus, observed heterozygosity $\left(\mathrm{H}_{0}\right)$, and the identification rate (IR). $\mathrm{H}_{0}$ was estimated for each type of EST-SSR marker. IR represents the degree of polymorphism of each marker suitable for genotype distinctness and was calculated as $\frac{1}{n} \sum_{i=1}^{n} P i$ where $P i$ is the rate of identified genotypes across all individuals at $i$ locus and $n$ is the number of observed loci. The value of IR varies between 1 (all the individuals are distinct at all loci) and 0 (all individuals

Table I: Citrus accessions used in this study for STMS screening maintained at the Corsican citrus germplasm.

\begin{tabular}{llll}
\hline Latin name & Commun name & Varietal name & Accession number \\
\hline Citrus clementina Hort. ex Tan. & clementine & Nules & SRA 498 \\
Citrus sinensis (L.) Osb. & sweet orange & Washington navel & SRA 555 \\
Citrus reshni Hort. ex Tan. & mandarin & Cleopatra & ICVN 0II0066 \\
Citrus deliciosa Ten. & mandarin & Willow leaf & SRA I33 \\
Citrus aurantium L. & sour orange & Morocco & ICVN 0II0038 \\
Citrus paradisi Macf. & grapefruit & Marsh & SRA 293 \\
Citrus medica L. & citron & Corsican & SRA 6I3 \\
Citrus aurantifolia (Christm.) Swing. & lime & Mexican & SRA I40 \\
Citrus limettioïdes Tan. & lime & Brazil sweet & SRA 697 \\
Citrus limon (L.) Burm. & lemon & Lisbon Foothill & SRA I96 \\
Citrus maxima (Burm.) Merr. & pummelo & Sans pépin & SRA 7I0 \\
Citrus maxima (Burm.) Merr. & pummelo & Pink & SRA 322 \\
Citrus hystrix D.C. & combava & Kindia & SRA 630 \\
Poncirus trifoliata (L.) Raf. & trifoliate orange & Rubidoux & ICVN 0II0128 \\
Fortunella japonica (Thunb.) Swing. & kumquat & Marumi & SRA 482 \\
Severinia buxifolia (Poir.) Ten. & box orange & & ICVN 0II0249
\end{tabular}


have a same molecular profile at any locus). An ANOVA was applied as statistical analysis to test the effect of the SSR features on diversity parameters.

To determine the genetic diversity structure and relationships between species we scored the SSR profile at 41 loci for each citrus sample by coding the presence (1) and the absence ( 0 ) of each allele. Genetic distance between each citrus genotype was estimated by calculating the Dice dissimilarity index [39]. A dendrogram was constructed with the Neighbour joining method [40]. This analysis was performed with the "DARwin" software developed by CIRAD (Montpellier, France). We have calculated the percentage of heterozygous loci of each of the 15 genotypes (Severinia buxifolia was not included in this analysis) and also the percentage of polymorphic and monomorphic heterozygous loci between each pair of genotypes. The percentage of mappable loci in each hypothetical genotype association was estimated by the addition of the rate of heterozygous loci from two parents and avoiding to taking account twice the commune markers.

\section{Results \\ EST-SSRs frequency and $G O$ representation}

1692 SSRs (excepted mononucleotide unit) were identified among 11391 unigenes from 37000 EST clones. We first analyzed the type nucleotide repetition in the SSRs. Some unigenes contained more than one microsatellite sequences and at the end, 1501 unigenes (13\%) had at least one SSR. Functional characterization of ESTs was performed assigning Gene Ontology annotations [35], with the BLAST2GO software [36]. To provide a general representation of the annotation, the Slim GO Classification was obtained (see Materials and Methods), for both the whole set of ESTs and the subset displaying SSRs. ESTs with SSRs were present in every major Slim GO category, and no significant differences could be found with respect the whole EST collection (Fig. 1).

The different SSRs found among our Clementine EST library and their frequency were: the most common trinucleotide repeats (53.9\%) followed by dinucleotide repeats $(37.6 \%)$, tetranucleotide repeats $(3.7 \%)$, hexanucleotide repeats $(2.4 \%)$ compound repeats $(2 \%)$ and the less abundant pentanucleotide repeats $(0.4 \%)$.

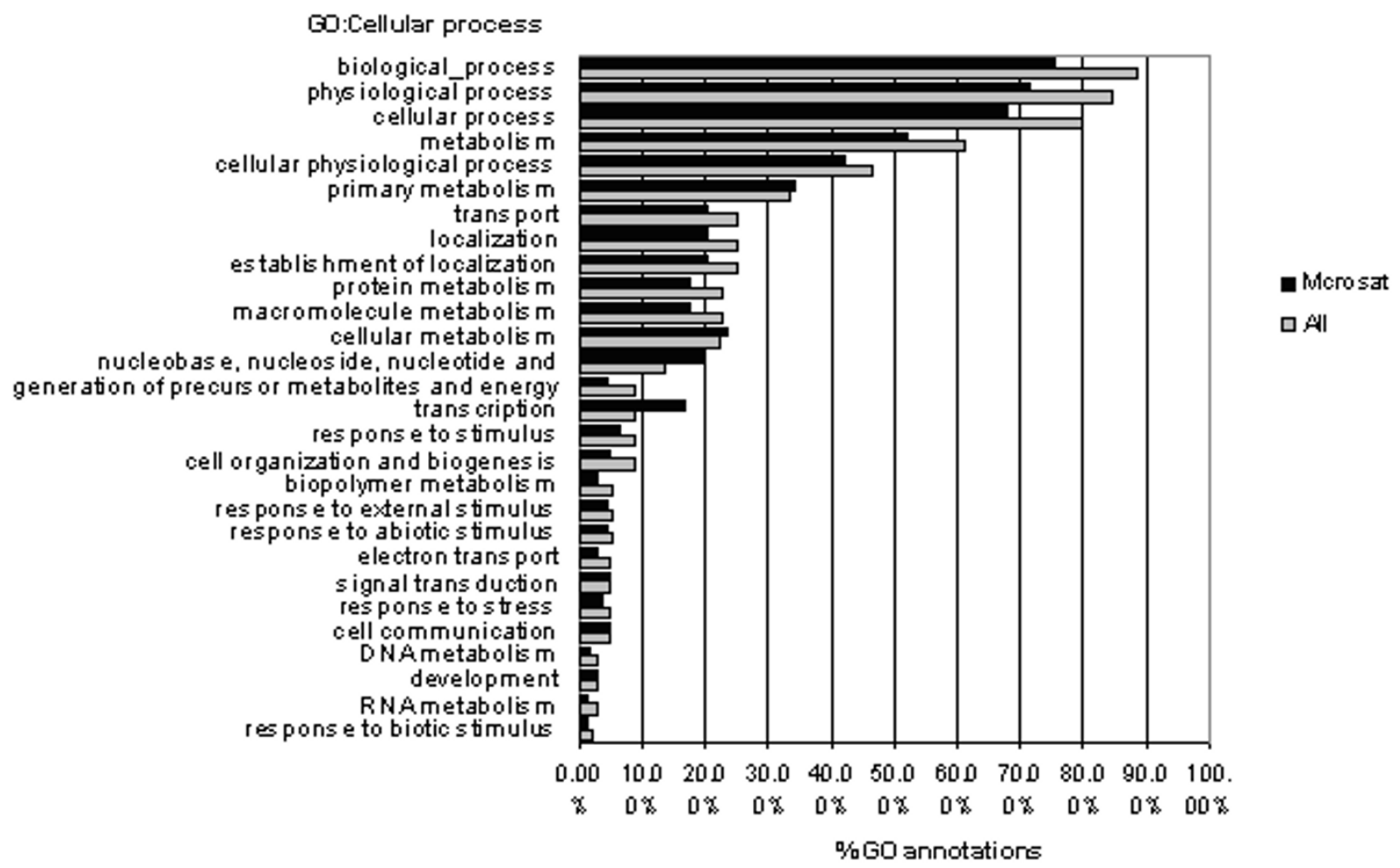

Figure I

Comparison of the unigenes distribution in MIPs function categories between the citrus EST collection and the ESTs that contain SSR. 


\section{Distribution of di or trinucleotide SSRs on ESTs}

The SSRs display preferential location along EST sequences from clementine EST database [19] was, with a high concentration of these before the $100^{\text {th }}$ nucleotide from the 5' extremity (75\%). The analysis of the SSR type showed a difference on distribution along the EST sequence (Fig. 2). Dinucleotide microsatellites were located preferentially at the beginning (5'part) of the cDNA (50\% of the total were located before the $100^{\text {th }}$ nucleotide) and in the UTR (75\%). Trinucleotide SSRs were less concentrated at the beginning of the 5 ' terminal region of the cDNA sequence $(25 \%)$ when compared to dinucleotide SSRs. Microsatellites were localized either inside, either outside the translated region (TR). Since the absence of a stop codon in some cDNA sequences (the sequencing was not complete in the 3' extremity), it wasn't possible to detect any translated sequences or ORFs (open reading frame) for the cDNA sequences corresponding to the EST-SSR markers $\mathrm{N}^{\circ} 16,21,26,34$ and 43. For EST sequences where the TR was detected, dinucleotide SSRs were preferentially concentrated $(75 \%$ of them) in untranslated regions (UTR). Trinucleotide microsatellites were equitably distributed inside and outside the TR of the ESTs (48\% and 52\% respectively).

\section{Development of EST-SSR markers}

A set of 48 pairs of primers was randomly chosen among the 1692 microsatellites that matched with identified genes sequences from nucleic acid data bases (EMBL or NCBI) to amplify 23 dinucleotide SSRs and 25 trinucleotide SSRs. Among them, 7 did not amplify even clementine suggesting that the selected primers were not adapted or that the PCR product was too large to be amplified. 41 primer pairs amplifying DNA fragment in Clementine were presented in Table 2. In order to check the redun-

\section{position of the SSR starting from the 5 ' end of the EST's sequence}

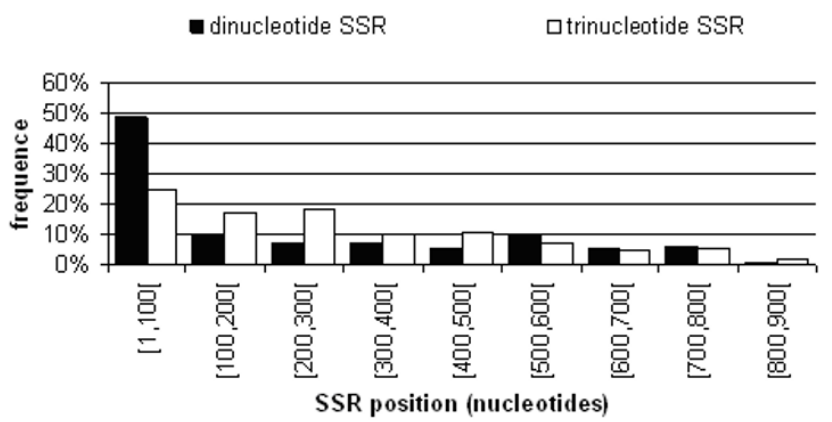

Figure 2

Position of the dinucleotide and trinucleotide SSRs from 5' end EST sequences. dancy or the novelty of those markers, we compared by BLASTn the sequences of EST clones supporting the development of EST-SSR markers in clementine with those published by Chen et al [23]. We have not detected any similarity between both sets of markers. The amplified DNA profile of EST-SSR markers $\mathrm{N}^{\circ} 115$ and $\mathrm{N}^{\circ} 482$ were multi-bands suggesting genome duplications of corresponding genes or nonspecific PCR amplification. We have also compared the expected size of DNA fragment containing each SSR and flanked by primers (calculated from the EST sequence), and the size of corresponding amplified fragments from genomic DNA of Clementine (estimated on gel electrophoresis) (Table 2). The observed PCR product sizes were mainly equal to the expected ones with differences minus than 10 nucleotides. These small variations could be associated to errors during ESTs sequencing or in size estimation on gel electrophoresis. For 6 EST-SSR markers $\left(\mathrm{N}^{\circ} 21,25,34,203,228\right.$ and 430) variations were greater than 30 nucleotides with a maximum of 270 bases of increase of the DNA fragment size for marker $N^{\circ} 430$. In those markers, we suspected the presence of introns in the amplified DNA fragments.

The 39 single EST-SSR markers were used to amplify the DNA of 16 genotypes representing a wide genetic variation of the Corsican citrus germplasm. Amplifications were successful for all the citrus genotypes with all primer pairs excepted for 3 markers which did not amplify any DNA fragment for Box orange (Severinia buxifolia). This genotype was considered to a member of the Citrinae subtribes as true citrus genera (Poncirus, Fortunella and Citrus).

Observed size variations in amplified DNA fragments were always correlated to the size of the repeated sequence unit of each SSR suggesting that the polymorphism was only related to the difference of repetition number of SSR. On the figure 3 is represented the polymorphism detected with the trinucleic microsatellite marker $N^{\circ} 164$. Note that the size differences between each DNA fragments were equal or multiple of 3 (181/187 bases, 181/190 bases, $184 / 181$ bases for respectively Nules clementine, Morocco sour orange and Mexican lime). The sequencing of these different SSR alleles confirmed that the size variation was due to the difference in the number of repeats unit.

\section{Position and SSR type effect on polymorphism}

Polymorphism, number of allele per locus and number of genotypes per locus for the 16 dinucleic and 23 trinucleic SSRs when compared to their respective position on the EST sequence (Table 3). Without any distinction about the type of SSR we have observed an effect of the SSR position on the polymorphism. The polymorphism obtained was greater when SSRs were in UTRs (86\% versus $67 \%$ ) whatever the type of repeats. Considering only the type of 
Table 2: Primers sequences of a random selection of 4I EST-STMS.

\begin{tabular}{|c|c|c|c|c|c|c|c|}
\hline SSR name & EST Accession number & SSR Type & $\begin{array}{l}\text { Forward Primer } \\
\left.\text { Sequence (5' to } 3^{\prime}\right)\end{array}$ & $\begin{array}{l}\text { Reverse Primer } \\
\left.\text { Sequence ( } 5^{\prime} \text { to } 3^{\prime}\right)\end{array}$ & $\begin{array}{l}\text { Expected Product size } \\
\text { (b) }\end{array}$ & $\begin{array}{l}\text { Observed product size } \\
\text { (b) }\end{array}$ & SSR localization \\
\hline 5 & DY262823 & $(A G) I I$ & $\begin{array}{l}\text { AAGGCATAGCAAAG } \\
\text { AAGCCA }\end{array}$ & $\begin{array}{l}\text { CTTGGGCCATCATC } \\
\text { TACTGG }\end{array}$ & 203 & $204 / 236$ & $\mathrm{cds}$ \\
\hline 10 & DY263095 & $(\mathrm{TC}) 9$ & $\begin{array}{l}\text { TCAAAGTTGATTTTC } \\
\text { ATTTGCC }\end{array}$ & $\begin{array}{l}\text { GGGAACATCATAGT } \\
\text { CGGTGC }\end{array}$ & 165 & $178 / 180$ & 5' UTR \\
\hline 16 & DY264I79 & $(\mathrm{TC}) 13$ & $\begin{array}{l}\text { ACCTGAGCCCTTTTTT } \\
\text { GGTTT }\end{array}$ & $\begin{array}{l}\text { GCCAGATCAAGGCT } \\
\text { CAAATC }\end{array}$ & 136 & $133 / 136$ & nd. \\
\hline 20 & DY264355 & (AT)7 & $\begin{array}{l}\text { AAAAACACCTGTGG } \\
\text { GACAGC }\end{array}$ & $\begin{array}{l}\text { TAAACACTCCAGGC } \\
\text { ACCCTC }\end{array}$ & 123 & 125 & 5' UTR \\
\hline 21 & DY264533 & $(\mathrm{TC}) 8$ & $\begin{array}{l}\text { TGATCAGCAACCAA } \\
\text { TAACCG }\end{array}$ & $\begin{array}{l}\text { AGTCCGTCGTTTGT } \\
\text { GATGTG }\end{array}$ & 240 & 240 & nd. \\
\hline 25 & DY264633 & $(\mathrm{TC}) 6$ & $\begin{array}{l}\text { CGGTCAGGTCCTCA } \\
\text { CATACA }\end{array}$ & $\begin{array}{l}\text { TGATCTTCTTCGCCT } \\
\text { CCATT }\end{array}$ & 206 & 350 & 5' UTR \\
\hline 26 & DY265I29 & $(\mathrm{TC}) 6$ & $\begin{array}{l}\text { GTTCTCCCCTTCCC } \\
\text { TCTCTG }\end{array}$ & $\begin{array}{l}\text { CCAATGATGAAAGC } \\
\text { CAAACA }\end{array}$ & 268 & 300 & nd. \\
\hline 34 & DY265633 & $(\mathrm{TA}) 6$ & $\begin{array}{l}\text { TTATGCTCCGGCTG } \\
\text { CTTAGT }\end{array}$ & $\begin{array}{l}\text { AAAAGCCACTCGTT } \\
\text { ACACGG }\end{array}$ & 165 & 166 & nd. \\
\hline 43 & DY266190 & $(\mathrm{TA}) 6$ & $\begin{array}{l}\text { CGAACCACTCCCCA } \\
\text { TCTCT }\end{array}$ & $\begin{array}{l}\text { TGATGGTGGTGTTC } \\
\text { TCCTTG }\end{array}$ & 130 & 330 & nd. \\
\hline 115 & DY274953 & $(\mathrm{TA}) 6$ & $\begin{array}{l}\text { СССССТСТТСТTТСА } \\
\text { САСАА }\end{array}$ & $\begin{array}{l}\text { GGTGAGCAGCCATC } \\
\text { TTCTTC }\end{array}$ & 136 & $136 / 140$ & 5' UTR \\
\hline 159 & DY280390 & $(\mathrm{GA}) 10$ & $\begin{array}{l}\text { TTTTTGGCTTTCTGG } \\
\text { GTTTG }\end{array}$ & $\begin{array}{l}\text { GCTCCACTGGGATA } \\
\text { GCTGAG }\end{array}$ & 243 & multibands & 5' UTR \\
\hline 282 & DY294I29 & $(\mathrm{CT}) 6$ & $\begin{array}{l}\text { GGACCAGAAGCAGG } \\
\text { TTTTGT }\end{array}$ & $\begin{array}{l}\text { AAAGAGCGATGACC } \\
\text { CAAAAA }\end{array}$ & 201 & 187/201 & cds \\
\hline 295 & DY294759 & (TC)6 & $\begin{array}{l}\text { CACCTTCTCAGGCA } \\
\text { ATCTCC }\end{array}$ & $\begin{array}{l}\text { TTGAGCGATGTGAA } \\
\text { GAGGTG }\end{array}$ & 133 & 134 & cds \\
\hline 482 & DY296883 & $(\mathrm{GA}) 10$ & $\begin{array}{l}\text { СССССТСТTTTTСТС } \\
\text { TTССА }\end{array}$ & $\begin{array}{l}\text { TTCTGGGCTGGTAG } \\
\text { GTTCAG }\end{array}$ & 215 & $210 / 214$ & cds \\
\hline 652 & DY26284I & (GA)II & $\begin{array}{l}\text { TCTTCTGCTGGAAA } \\
\text { CAAGCC }\end{array}$ & $\begin{array}{l}\text { TGGAAGAGAAGAAA } \\
\text { CGGTGG }\end{array}$ & 221 & multibands & 5' UTR \\
\hline 817 & DY28785I & (TA) 17 & $\begin{array}{l}\text { CCCAGCTTCCAGAG } \\
\text { AAGAGA }\end{array}$ & $\begin{array}{l}\text { GTCAAGAATCAAGC } \\
\text { AGGCGT }\end{array}$ & 195 & 195/219 & 5' UTR \\
\hline 830 & DY284947 & (TC)6 & $\begin{array}{l}\text { TTCATGGCAGCTTG } \\
\text { AGTTTC }\end{array}$ & $\begin{array}{l}\text { TTGGTTTCTTTTGGG } \\
\text { GATCA }\end{array}$ & 197 & 197/199 & cds \\
\hline 1527 & DY292I05 & $(\mathrm{TC}) 6$ & $\begin{array}{l}\text { GCGCGATCACTCTC } \\
\text { TTTCTT }\end{array}$ & $\begin{array}{l}\text { ATCGGGTTTGGATT } \\
\text { AGGGAC }\end{array}$ & 114 & $114 / 116$ & cds \\
\hline 32 & DY265504 & (CAG)6 & $\begin{array}{l}\text { CAGATCCTATTGCA } \\
\text { GAGGCA }\end{array}$ & $\begin{array}{l}\text { GCCCATTTGTATTGC } \\
\text { CATTT }\end{array}$ & 175 & 178 & 5' UTR \\
\hline 67 & DY268562 & $(A G C) 5$ & $\begin{array}{l}\text { ATGTGGCTCCCTCT } \\
\text { TCTCCT }\end{array}$ & $\begin{array}{l}\text { GTGCATAACTGGGC } \\
\text { CGTACT }\end{array}$ & 175 & 192/195 & 5' UTR \\
\hline 92 & DY272212 & (ATC)5 & $\begin{array}{l}\text { CGCAGCTTTTGCAT } \\
\text { GTTTTA }\end{array}$ & $\begin{array}{l}\text { TGCTGCTAACCCAC } \\
\text { AGACAG }\end{array}$ & 242 & 253 & cds \\
\hline 93 & DY272212 & $(\mathrm{CTT}) 5$ & $\begin{array}{l}\text { TGCATTTTCACCTCA } \\
\text { GCAAC }\end{array}$ & $\begin{array}{l}\text { GGGAGAGAGAGAAA } \\
\text { GCCAGC }\end{array}$ & 212 & 210 & cds \\
\hline 116 & DY274953 & $(A G A) 7$ & $\begin{array}{l}\text { GAATTGGGAGGACG } \\
\text { AACTGA }\end{array}$ & $\begin{array}{l}\text { CGAGCCCTAGACAG } \\
\text { AGATGG }\end{array}$ & 252 & $249 / 252$ & cds \\
\hline 117 & DY275245 & (TCA)6 & $\begin{array}{l}\text { AACAAACCCAGAAC } \\
\text { ACTGCC }\end{array}$ & $\begin{array}{l}\text { TGAGTGTGGGCGTA } \\
\text { GATTGA }\end{array}$ & 108 & 108 & 5' UTR \\
\hline 121 & DY275927 & $($ TAA $) 9$ & $\begin{array}{l}\text { TCCCTATCATCGGC } \\
\text { AACTTC }\end{array}$ & $\begin{array}{l}\text { CAATAATGTTAGGCT } \\
\text { GGATGGA }\end{array}$ & 181 & 180 & 3'UTR \\
\hline 137 & DY277386 & $(\mathrm{CAA}) 5$ & $\begin{array}{l}\text { CGTCTTGCTCGCTG } \\
\text { TATCTG }\end{array}$ & $\begin{array}{l}\text { TCGCTTTTTGGGATTT } \\
\text { GAGAC }\end{array}$ & 166 & 166 & 5' UTR \\
\hline 154 & DY279967 & $(\mathrm{GCC}) 5$ & $\begin{array}{l}\text { AAGCCTCAAGTCAA } \\
\text { GGCAAA }\end{array}$ & $\begin{array}{l}\text { GCCCCATTTTGTATG } \\
\text { GAGTG }\end{array}$ & 107 & 105/108 & 5' UTR \\
\hline 164 & DY281040 & $(\mathrm{GCC}) 5$ & $\begin{array}{l}\text { GTTTTCAGCTGGATT } \\
\text { CGAGG }\end{array}$ & $\begin{array}{l}\text { CACGTGTCCTCCTG } \\
\text { GAACTT }\end{array}$ & 180 & $181 / 187$ & cds \\
\hline 175 & DY281748 & (CAG)6N38(GCA)6 & $\begin{array}{l}\text { ACAGCAACCCCAGT } \\
\text { САСТCT }\end{array}$ & $\begin{array}{l}\text { CGCTCCTCGATTTG } \\
\text { AAGAAG }\end{array}$ & 252 & 252 & 5' UTR \\
\hline 179 & DY282259 & (CTT)5 & $\begin{array}{l}\text { TTCTCTCTCTCGAG } \\
\text { CTTCGC }\end{array}$ & $\begin{array}{l}\text { CCCAATCATCCTCC } \\
\text { GTTAGA }\end{array}$ & 210 & 220 & $\mathrm{cds}$ \\
\hline 196 & DY283426 & $(\mathrm{CGC}) 5$ & $\begin{array}{l}\text { TCTTCTTCCCTGCTT } \\
\text { TTCCA }\end{array}$ & $\begin{array}{l}\text { ATCAAGGAGATCCA } \\
\text { TGTGGG }\end{array}$ & 274 & 275 & cds \\
\hline 203 & DY284275 & (CTT)5 & $\begin{array}{l}\text { CTTCACAACCAAGG } \\
\text { CCATTT }\end{array}$ & $\begin{array}{l}\text { CTGTGTGCGAGCGT } \\
\text { ATCACT }\end{array}$ & 205 & 205 & cds \\
\hline 228 & DY286984 & $(\mathrm{GAG}) 5$ & $\begin{array}{l}\text { TGAAGGTGCTAGGA } \\
\text { TTGGCT }\end{array}$ & $\begin{array}{l}\text { CGGACACTCAAAAG } \\
\text { CTGACA }\end{array}$ & 238 & 508 & 5' UTR \\
\hline 238 & DY288340 & (TTC)5 & $\begin{array}{l}\text { CATGTTTCATTGCAA } \\
\text { ATGCC }\end{array}$ & $\begin{array}{l}\text { TCTGGACATTCCAT } \\
\text { CACCAA }\end{array}$ & 272 & 370 & 5' UTR \\
\hline 338 & DY299973 & $(\mathrm{CTT}) \mathrm{II}$ & $\begin{array}{l}\text { TTTCTAAAATTTCCT } \\
\text { TCATGGC }\end{array}$ & $\begin{array}{l}\text { CAGGTGAAATCTCA } \\
\text { TCGCCT }\end{array}$ & 204 & $204 / 216$ & 5' UTR \\
\hline 418 & DY274485 & $(\mathrm{AAT}) 5$ & $\begin{array}{l}\text { AAAACAAACGCCAC } \\
\text { CTAAATG }\end{array}$ & $\begin{array}{l}\text { CAGCAGCTGAAAAC } \\
\text { ACCTGA }\end{array}$ & 134 & 135 & 3'UTR \\
\hline 430 & DY275609 & (AAT)7NI5(AGC)7 & $\begin{array}{l}\text { CCGATACAGCACAA } \\
\text { AGCAAA }\end{array}$ & $\begin{array}{l}\text { TGGAAAGAGAGAAG } \\
\text { CCAAGC }\end{array}$ & 129 & 130 & $\mathrm{cds}$ \\
\hline 432 & DY275609 & $(\mathrm{GAG}) 5$ & $\begin{array}{l}\text { GAGCTCAAAACAAT } \\
\text { AGCCGC }\end{array}$ & $\begin{array}{l}\text { CATACCTCCCCGTC } \\
\text { CATCTA }\end{array}$ & 226 & 330 & cds \\
\hline 818 & DY28785I & (TCT)6 & $\begin{array}{l}\text { GTAGATTCGTTCAA } \\
\text { GGCCCA }\end{array}$ & $\begin{array}{l}\text { GTGAAGCTGGAAGA } \\
\text { GATGGC }\end{array}$ & 134 & 135 & 5' UTR \\
\hline 1210 & DY29500I & (ATC)5 & $\begin{array}{l}\text { GCCAAAATGCATGT } \\
\text { TCAAGA }\end{array}$ & $\begin{array}{l}\text { GTGCCAATGATGAT } \\
\text { CACGTC }\end{array}$ & 175 & 183 & 5' UTR \\
\hline 1388 & DY289396 & $(G G A) 6$ & $\begin{array}{l}\text { AAAACAAAGCACCC } \\
\text { AGATCG }\end{array}$ & $\begin{array}{l}\text { ACGGCAGCAACGAG } \\
\text { ATAAGT }\end{array}$ & 138 & 139 & cds \\
\hline
\end{tabular}

Both the expected PCR product size and observed product size are base number (b), multibands mean a non specific amplification or multilocus profile. Cds: Coding sequence; 3'UTR or 5'UTR 3' end or 5' end of untranslated region 


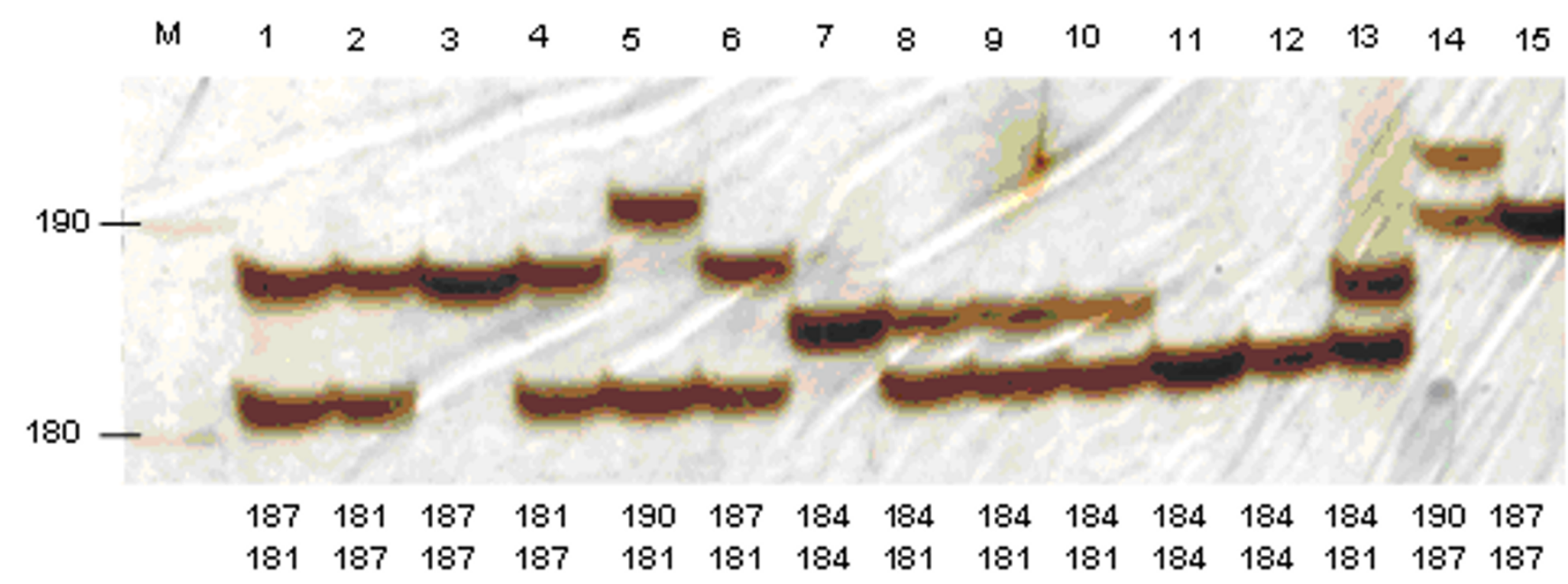

Figure 3

Polymorphism of the trinucleotide microsatellite (EST I 64 STMS) among citrus genotypes detected by silver nitrate staining gel electrophoresis. Below the photography size allelic interpretation of each genotype is detailed. The order of the sample is the following: Invitrogen 10 bp ladder (Lane M), 'Nules' clementine (lane I), 'Washington Navel' sweet orange (lane 2), 'Cleopatra' mandarin (lane 3), 'Willow leaf' mandarin (lane 4), 'Morocco' sour orange (lane 5), 'Marsh' grapefruit (lane 6), 'Corsican' citron (lane 7), 'Mexican' lime (lane 8), 'Brazil sweet' lime (lane 9), 'Lisbon Foothill' lemon (lane I0), 'Sans pepin' pummelo (lane II), 'Pink' pummelo (lane I2), 'Kindia' combava (lane I3), 'Rubidoux' trifoliate orange (lane I4), 'Marumi' kumquat (Lane I5).

repeated unit, differences were also observed. If the percentage of polymorphic loci was quite similar between trinucleic SSRs (83\%) and dinucleic SSRs (80\%), for the two last indicators of marker diversity the effect of unit repeat was significantly different. Dinucleic repeated units revealed significant higher polymorphism than trinucleic repeated units with 7.3 versus 4.1 alleles per locus $(\mathrm{P}=$ $0.015)$, and 0.61 versus 0.29 for the IR $(P=0.010)$. If we combine parameters, type and position, differences were particularly important for SSRs localized in UTR. In this situation, dinucleic repeats had a number of alleles per locus greater than trinucleic repeats $(7.9$ versus 4.4$)$ and a rate of identification 2 fold greater ( 0.66 versus 0.29$)$. The higher value of alleles per locus for dinucleic SSRs could be related to the higher percentage of heterozygous loci ( $54 \%$ versus $29 \%$ for trinucleic SSRs).

\section{EST-SSR markers for genetic mapping}

Heterozygosity of genotypes is a key component for genetic mapping on F1 progenies classically used for citrus genetic mapping. Based on a unique F1 progeny obtained from a cross between two heterozygous genotypes it is possible to develop a genetic map for each parent. Among our genotypes it varies from $8 \%$ for citron to $58 \%$ for Brazil Sweet lime (Table 4). Excepted citron, the heterozygosity of other citrus genotypes is higher than $23 \%$. In order to estimate the rate of mappable EST-SSR markers in each putative F1 progeny we have considered the percentage of

Table 3: Comparison of polymorphism parameters between dinucleotide and trinucleotide EST-SSR located in untranslated region (UTR) or in translated region (TR)

\begin{tabular}{|c|c|c|c|c|}
\hline & SSR type & SSR in TR & SSR in UTR & Total \\
\hline \multirow[t]{3}{*}{$\%$ of polymorphic loci } & dinucleotide & 67 & 83 & 80 \\
\hline & trinucleotide & 67 & 93 & 83 \\
\hline & indistincte & 67 & 86 & 82 \\
\hline \multirow[t]{3}{*}{ Number of allele per locus } & dinucleotide & 5,3 & 7,9 & 7,3 \\
\hline & trinucleotide & 3,6 & 4,4 & 4,1 \\
\hline & indistincte & 4 & 5,9 & 5,25 \\
\hline \multirow[t]{3}{*}{ Identification rate per locus } & dinucleotide & 0,44 & 0,66 & 0,61 \\
\hline & trinucleotide & 0,31 & 0,29 & 0,29 \\
\hline & indistincte & 0,34 & 0,44 & 0,41 \\
\hline
\end{tabular}


heterozygous loci, polymorphic and monomorphic between two genotypes in all putative combinations (Table 4). We have not considered Severinia buxifolia in this table because it is sexually incompatible with other true citrus varieties and so unsuitable for progeny creation for genetic programs. Heterozygous loci polymorphic between two genotypes could be used as anchored markers suitable for comparative genetic maps (sinteny). Higher values were observed between highly heterozygous species like Morocco sour orange (45\%) and Marsh grapefruit (43\%) with $29 \%$ of loci usable for comparative mapping. At the opposite, whatever the combined genotype, very few loci (less $10 \%$ ) were available for sinteny in all combinations involving citron that is the less heterozygous citrus specie. In general, combinations including interspecific hybrids such as limes, lemon, grapefruit, orange, and sour orange gave the highest percentage of EST-SSR markers suitable for sinteny ( $>20 \%)$. Kindia combava which is wild citrus specie is heterozygous as interspecific hybrids (43\%) and is also characterized by high percentage of suitable markers for sinteny whatever the parental partner excepted with Corsican citron and Pink pummelo. We have estimated also the percentage of monomorphic heterozygous loci (upper part of the table 4). If the allelic segregation could be expected in these loci, the parental origin for inherited allele could not be assigned and then the information related to meiosis in both genotypes is lost. These markers were usually included in segregation data set for genetic map construction from F1 progeny, with the hypothesis of equal recombination rate and normal segregation between male and female genomes. In few combinations the percentage of heterozygous and monomorphic loci is quite high for instance for clementine/sweet orange $(20 \%)$ or Brazil sweet lime/lemon (21\%). Nevertheless, excepted pairs involving clementine and sweet orange combined with Willow leaf mandarin, sour orange and grapefruit, the percentage of heterozygous loci showing a same profile between two genotypes was very low near zero.

Estimated percentages of mappable loci in each F1 progeny were presented in Table 5 . The mean value of mappable loci calculated on the basis of all results was $57 \%$ for this set of genotypes. In details, higher values were observed for different combinations involving Brazil sweet lime with different genotypes, as Marsh grapefruit $(80 \%)$, Valencia late sweet orange $(78 \%)$ or Morocco sour orange $(77 \%)$. It is quite interesting to note that the combination of the two more heterozygous genotypes (Brazil sweet lime and Lisbon lemon) produced a relatively low percentage of mappable marker (65\%) due to high level of commune markers ( $21 \%$ of polymorphic plus $21 \%$ of monomorphic). The less efficient combination was observed for Corsican citron associated with Cleopatra mandarin $(29 \%)$ due to the high homozygous level of these genotypes.

\section{EST-SSR markers for genetic diversity analysis}

In order to evaluate the ability of EST-SSR markers to be used for systematic studies a cluster analysis of genetic diversity was done combining polymorphism data of dinucleic and trinucleic EST-SSR (Fig. 4). The sixteen genotypes were clearly differentiated and the relationships between them were organized around two major groups, clearly defined: The first group associated mandarins, orange, sour orange, grapefruit and pummelo. The second one was constituted mainly by the acidic species such as lemon, limes, citron and combava. We can note that trifo-

Table 4: Percentage of heterozygous loci, for each citrus genotype (diagonally bold characters); percentage of monomorphic heterozygous loci between each pair of genotype (italic characters in the upper right size of the table) and percentage of polymorphic heterozygous loci between two genotypes (normal characters in the left down part of the table).

\begin{tabular}{cccccccccccccccccc}
\hline IN* & Varieties & 1 & 2 & 3 & 4 & 5 & 6 & 7 & 8 & 9 & 10 & 11 & 12 & 13 & 14 & 15 \\
\hline 1 & Clementine & $\mathbf{3 6}$ & 20 & 3 & 18 & 11 & 9 & 0 & 0 & 3 & 6 & 0 & 0 & 0 & 0 & 3 \\
2 & Valencia late sweet orange & 3 & $\mathbf{4 0}$ & 6 & 15 & 11 & 12 & 0 & 0 & 3 & 6 & 0 & 3 & 0 & 0 & 3 \\
3 & Cleopatra mandarin & 11 & 3 & $\mathbf{2 4}$ & 6 & 3 & 0 & 0 & 0 & 3 & 3 & 0 & 0 & 0 & 0 & 3 \\
4 & Willow leaf mandarin & 9 & 3 & 12 & $\mathbf{4 3}$ & 9 & 9 & 0 & 0 & 3 & 3 & 0 & 3 & 0 & 0 & 3 \\
5 & Morocco sour orange & 20 & 23 & 11 & 15 & $\mathbf{4 5}$ & 3 & 0 & 0 & 3 & 6 & 0 & 3 & 0 & 0 & 3 \\
6 & Marsh grapefruit & 12 & 18 & 12 & 12 & 29 & $\mathbf{4 3}$ & 0 & 3 & 0 & 0 & 0 & 3 & 0 & 0 & 0 \\
7 & Corsican citron & 6 & 3 & 3 & 3 & 3 & 3 & $\mathbf{8}$ & 3 & 0 & 0 & 3 & 0 & 0 & 0 & 0 \\
8 & Mexican lime & 24 & 21 & 15 & 24 & 24 & 18 & 3 & $\mathbf{4 1}$ & 9 & 6 & 3 & 3 & 3 & 0 & 0 \\
9 & Brazil sweet lime & 20 & 17 & 11 & 24 & 23 & 21 & 3 & 24 & $\mathbf{5 8}$ & 21 & 6 & 6 & 6 & 0 & 6 \\
10 & Lisbon lemon & 21 & 15 & 15 & 24 & 24 & 21 & 3 & 24 & 21 & $\mathbf{4 9}$ & 9 & 3 & 0 & 3 & 6 \\
11 & Sans pepins pummelo & 15 & 15 & 12 & 15 & 18 & 12 & 3 & 15 & 18 & 9 & $\mathbf{3 2}$ & 0 & 0 & 0 & 0 \\
12 & Pink pummelo & 6 & 9 & 9 & 9 & 6 & 12 & 3 & 12 & 12 & 9 & 12 & $\mathbf{2 7}$ & 0 & 0 & 0 \\
13 & Kindia combava & 21 & 21 & 15 & 21 & 24 & 18 & 6 & 21 & 24 & 21 & 21 & 9 & $\mathbf{4 3}$ & 0 & 0 \\
14 & Pomeroy trifoliate orange & 11 & 17 & 9 & 12 & 17 & 18 & 3 & 18 & 20 & 9 & 15 & 12 & 21 & $\mathbf{2 9}$ & 0 \\
15 & Marumi kumquat & 11 & 11 & 11 & 9 & 17 & 15 & 3 & 12 & 11 & 9 & 12 & 6 & 15 & 17 & $\mathbf{3 4}$
\end{tabular}

\footnotetext{
* Identification number
} 
Table 5: Percentages of mappable loci in each progeny derived from all genotype combinations.

\begin{tabular}{|c|c|c|c|c|c|c|c|c|c|c|c|c|c|c|c|}
\hline IN* & Varieties & 1 & 2 & 3 & 4 & 5 & 6 & 7 & 8 & 9 & 10 & 11 & 12 & 13 & 14 \\
\hline 1 & Clementine & & & & & & & & & & & & & & \\
\hline 2 & Valencia late sweet orange & 53 & & & & & & & & & & & & & \\
\hline 3 & Cleopatra mandarin & 46 & 55 & & & & & & & & & & & & \\
\hline 4 & Willow leaf mandarin & 52 & 65 & 49 & & & & & & & & & & & \\
\hline 5 & Morocco sour orange & 50 & 51 & 55 & 64 & & & & & & & & & & \\
\hline 6 & Marsh grapefruit & 58 & 56 & 55 & 65 & 56 & & & & & & & & & \\
\hline 7 & Corsican citron & 38 & 45 & 29 & 48 & 50 & 48 & & & & & & & & \\
\hline 8 & Mexican lime & 53 & 60 & 50 & 60 & 62 & 63 & 43 & & & & & & & \\
\hline 9 & Brazil sweet lime & 71 & 78 & 68 & 74 & 77 & 80 & 63 & 66 & & & & & & \\
\hline 10 & Lisbon lemon & 58 & 68 & 55 & 65 & 64 & 71 & 54 & 60 & 65 & & & & & \\
\hline 11 & Sans pepins pummelo & 53 & 57 & 44 & 60 & 59 & 63 & 34 & 55 & 66 & 63 & & & & \\
\hline 12 & Pink pummelo & 57 & 55 & 42 & 58 & 63 & 55 & 32 & 53 & 67 & 64 & 47 & & & \\
\hline 13 & Kindia combava & 58 & 62 & 52 & 65 & 64 & 68 & 45 & 60 & 71 & 71 & 54 & 61 & & \\
\hline 14 & Pomeroy trifoliate orange & 54 & 52 & 44 & 60 & 57 & 54 & 34 & 52 & 67 & 66 & 46 & 44 & 51 & \\
\hline 15 & Marumi kumquat & 56 & 60 & 44 & 65 & 59 & 62 & 39 & 63 & 75 & 68 & 54 & 55 & 62 & 46 \\
\hline
\end{tabular}

* Identification number

liate orange was included in this group even if it represents related genera. The last two genotypes, Severinia buxifolia and Fortunella japonica, were not included in any genetic clusters.

\section{Discussion}

Frequency, distribution, and polymorphism

From the 11391 unigenes obtained from 37000 EST [19], 1692 microsatellite sequences were identified. $14 \%$ of unigenes contain at list one microsatellite as already mentioned for other citrus resources by Chen et al. [23]. This

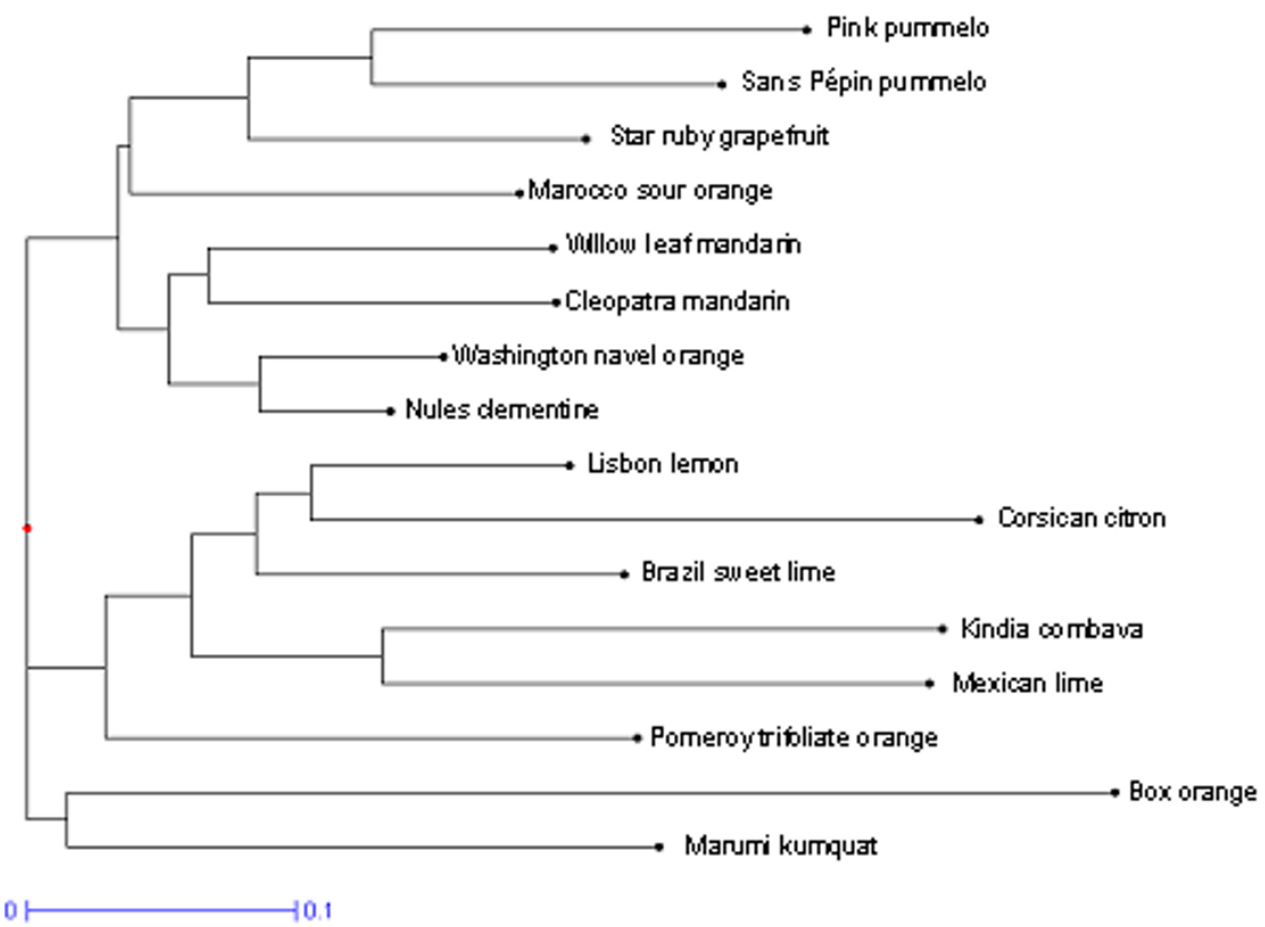

Figure 4

Dendrogram representing the structure of genetic diversity and relationships observed between the 16 citrus genotypes aimed by the polymorphism of the 39 single locus EST-STMS markers. 
value can be considered as quite high by taking account of the selection pressure that is applied on genes to maintain a lower diversity on the coding region. Nevertheless this frequency is higher than observed for dicotyledonous species ranged between $2.65 \%$ and $10.62 \%[41,42]$. The frequency is dependent on the presence or not of redundancy but also related to the parameters used for SSRs screening in the database mining. Varshney et al [43] reported that the frequency was about $5 \%$ when the minimum length for the detection of microsatellite was 20 nucleotides. In our study we were less drastic for the detection of SSR. We have fixed this criterion to a minimum of 6 repetitions for dinucleotide repeats ( 12 base pairs in length) and 5 for the others ( 15 base pairs in length for trinucleotide). This difference could explain our higher frequency of SSRs in ESTs without apparently any effect on polymorphism (see below). Trinucleotide and dinucleotide repeats were the most common SSRs in clementine ESTs (53.9\% and $37.6 \%$ respectively). These values reflect the predominance of trinucleotide and dinucleotide repeats in many EST plant species $[23,42-46]$ meanwhile a strong divergence was observed in a hexanucleotide repeat frequency. In many crops they were abundant with a frequency ranged between 13-26\%. In clementine ESTs they represent only $2.4 \%$ of overall SSRs.

Functional characterization of ESTs performed with GO annotation showed that all the main functional categories were represented. This is in agreement with previous results $[18,19]$. The EST- SSRs showed similar distributions in the GO Slim categories, and no functional group was overrepresented, indicating that there is no preference in the location of microsatellites with respect to function of the genes.

Relation between SSR polymorphism and phenotypic variation could be investigated in any MIPSs functional categories. Moreover, the EST-SSRs could represent a convenient and cheap way for genes mapping when compared to RFLP technique and sequencing. Unfortunately, the frequency of gene containing a SSR sequence is relatively low (14\%). Moreover less than $66 \%$ of the analyzed SSR were polymorphic. That means that less than $9 \%$ $(14 \% \times 66 \%)$ of the unigenes should be mapped by internal SSR markers. Seven of the 47 couples of primers amplified DNA fragments from clementine that were larger than expected suggesting the presence of introns. It is possible that the non amplification for the 9 other primers couples was also due to the presence of introns.

From the position analyze of SSRs in ESTs we founded that the majority of SSRs were located in the UTR and mostly $(75 \%)$ in the first hundred bases of the $5^{\prime}$ cDNA extremity. This non equal distribution of SSRs along the cDNA sequence was also reported in other crops such as rice, wheat and barley [17] but with some divergences. In barley, the majority of SSRs are present in the EST 3'sequences with a high proportion of dimeric and tetrameric SSRs despite tetrameric SSRs are quite absent in Clementine ESTs. As clementine EST clones were singlepass sequenced from their $5^{\prime}$ end and their main size were about 800 nucleotides [19], 3'end sequences of these ESTs were certainly under represented. The EST 3 ' end region was known to be also reached in microsatellites sequences $[44,45]$. As a consequence of this method of EST production, we believe that we have introduced a bias in the general distribution of the different SSRs along the clementine transcribed sequences. Nevertheless, few works described the abnormally high frequency of microsatellite in 5'UTR regions of plant genes, and a lower abundance in coding region or $3^{\prime}$ UTRs $[43,45]$. Our results seem to confirm this feature. This heterogeneous distribution of SSRs could be explained by the incidence of the SSR variability on the gene transcription and/or proteins structure integrity and function. In UTR, these microsatellites can be more variable without changing gene transcription and translation. The dominance of trimeric SSRs in TR can be explained by the suppression of non-trimeric SSRs in coding regions due to the risk of frame shift mutations that may occur when those microsatellites alternate in size of one unit. In the case of trimeric repeats, it is worth to note that this kind of microsatellite was distributed homogenously along ESTs. It could be hypothesized that trinucleotide SSR variations has less impact than dinucleotide variations in the gene functionality. Indeed, modification of the number of repeats of trinucleotide does not affect the reading frame. Furthermore, dimeric SSRs seem to be more polymorphic than trimeric ones and particularly in UTR with a putative higher allelic diversity combined with higher heterozygosity contributing to a powerful capacity for distinctness. These differences between repeated unit types were attenuated or disappeared when they were located in TR. However, the importance of this result has to be attenuated since we do not have an equal representation for each situation and a too low sampled marker set. Unfortunately, only 4 loci with di-SSRs in TR were detected when compared to 12 for trimeric SSRs and then the differences were not statistically significant.

\section{EST-SSR markers for citrus diversity}

Genetic diversity analysis and systematic is a classical application of SSR markers. For such application, the ability of one marker to differentiate germplasm accessions is an important characteristic. Due to their higher polymorphism, markers localized in UTR are more interesting than markers in TR. Moreover, better rate of accession identification have been obtained with dinucleotide markers (0.61) than with trinucleotide ones (0.29). 
The organization of genetic diversity obtained with ESTSSR is in agreement with the knowledge of the genetic relationships between Citrus species previously reported by studies using different markers for systematic analyses: morpho-physiological characters [47], biochemistry [48], isozymes [49,50], genomic SSR markers [13,14], CAPS markers [51], or RFLP and RAPD markers [52]. Three major ancestral species: mandarins, pummelos and citrons are at the origin of many cultivated hybrids. As well, the parental relation of limes and lemons with citrons was clearly demonstrated by all these studies. It is in agreement with the strong differentiation we observed between acidic citrus group (lime-lemon-citron) and the pummelo-mandarin (and their hybrids) group. Lemon is thought to be a natural hybrid of a citron and a lime $[47,48]$, or a hybrid of citron and sour orange [51,53]. Our results seem to comfort the participation of sour orange because 15 alleles specific from this genotype were detected in lemon since 10 from citron and only 3 from lime were observed. Nevertheless, we can not certify the parental combination because in our sampling the lime and citron groups were limited to a unique variety. The diversity of these groups were not represented as described previously $[13,14]$ and so few alleles from lemon (4) were still absent in the three putative parents of our study. Several hypotheses have also been proposed to explain the origin of Mexican limes: hybrids of citrons and papedas [48], tri-hybrid cross of citron, pummelo, and Microcitrus [47] or hybrid between citron and C. micrantha [51]. As for lemon the limited diversity of our analysis does not allow to discuss these hypotheses. Sour orange is a natural hybrid of a mandarin and a pummelo and in our analysis it is associated to the pummelo cluster. The participation of the two basic species, pummelo and mandarin, to the sweet orange formation is attested by the citrus taxonomy literature. However, some troubles still remain concerning the number of crosses between these two basic species. Barkeley et al. [14] suggested that sweet orange was derived from one or more backcrosses to the mandarin and then its genetic was makeup derived from mandarin and a small proportion from pummelo. Nicolosi et al. [51] have proposed a single cross based on equal proportions of alleles from mandarin and pummelo. Our results, with a common cluster of mandarin and sweet orange support the first hypothesis where sweet orange has a higher proportion of alleles from mandarin.

Compared to the phylogeny made with genomic SSR [14] a single difference was observed in our representation. It concerns the genetic diversity between citrus genera. The trifoliate orange (Poncirus trifoliata) joins the cluster of citron-limes-lemon while kumquat (Fortunella japonica) remains genetically distant to other citrus. In previous work [14] about genetic relationships based on genomic SSRs, the situation was inverted wherein Fortunella species were much more closely related to the four other Citrus (mandarins, pummelos, citrons and papedas), and the group of Poncirus accessions were very distant to all others. This difference could be related by the overrepresentation of kumquat diversity in our study or by a real difference of polymorphism rate between genomic SSRs and EST-SSRs. A similar study on a larger citrus sampling could be suitable to resolve this question. We can not compare the transferability of EST-SSR and genomic SSRs, but a large majority of EST-SSR markers could be used to investigate the genetic of citrus relatives. Indeed, only $10 \%$ of those EST-SSR markers gave unsuccessful amplification in Box orange (Severinia buxifolia).

\section{EST-SSR marker for citrus genome mapping}

Citrus have a juvenility period with around 5 years of duration limiting the possibility to work on a second generation of hybrids. Consequently a lot of citrus genetic maps are established on F1 progenies at interspecific [25] and intergeneric level [26-31]. In order to evaluate the proportion of mappable EST-SSR markers we have calculated the percentage of heterozygous markers informative for all combinations between 15 sexually compatible citrus genotypes, currently used or susceptible to be used in citrus genetic programs. Table 4 represents a tool for the selection of the sexual cross most suitable for a higher efficiency of mappable markers associated to the better situation for comparison of both parental maps. Higher percentages of markers are available to map secondary species of cultivated citrus than to establish genetic maps of the three basic taxa (citron, mandarin, pummelo). As a result, a very low rate of EST-SSR markers is usable to make comparative genetic mapping between these three basic taxa: it is only 3\% for Citron/Pummelo, 3\% for Citron/Mandarin (cv Cleopatra) and around 9\% for Pummelo (cv Pink)/Mandarin (cv Cleopatra).

It is clear that the best way to map the higher number of markers in a single progeny is to work on segregation of interspecific or intergeneric crosses. Citrus $\times$ Poncirus progenies have been highly investigated [11,54-59]. A recent work on EST genetic maps for Citrus sinensis and Poncirus trifoliata was published [59]. For these maps the authors have studied the segregation of 300 pairs of primers generating EST-SSR markers on the intergeneric progeny sweet orange $\times$ trifoliate orange. Among them 141 markers (47\%) were mapped and distributed as following: 122 markers $(40.7 \%)$ on sweet orange map, $59(19.7 \%)$ on trifoliate orange one and $40(13.3 \%)$ were commune to both. These values were very similar to those proposed in our work (table 4 and 5) where for the same parental cross we have estimated at $52 \%$ of of mappable EST-SSR markers and $40 \%, 29 \%$ and $17 \%$ respectively for orange, trifoliate orange maps and commune markers. This mapping work was done with a majority of non abundant SSRs in 
ESTs such as compound, tetra-, penta- and hexa-nucleotide repeats. Di and tri-nucleotide SSRs represent only $26.7 \%$ of the total studied SSR markers.

On the base of the genetic differentiation observed in our cluster analysis, it appears that in this frame, interesting progenies should be obtained from F1 hybrids between citron and pummelo, citron and mandarin, as well between poncirus or kumquat with citron or mandarin or pummelo. Such intrageneric progenies should probably have more interest for further QTLs analysis of quality traits.

\section{Conclusion}

We have observed a differential repartition of dinucleic and trinucleic SSRs in the clementine ESTs with a high concentration in UTR and more precisely in the 5'initial region (but without a default of representation of 3'UTR regions du to the strategy of EST sequencing). The degree of SSR polymorphism is strongly modified by the utility of coding regions. These two elements suggest that the natural selection should limit the number and the polymorphism of SSRs in coding translated sequences. ESTSSRs are useful for enhancing individual species map, but can be used as anchor probes for creating links between maps in comparative studies. With the appropriate progeny arise from crosses between interspecific or intergeneric hybrids as parents, we can expect to use up to $80 \%$ of the EST-SSR markers representing $9 \%$ of the global set of genes from all the identified function groups. We suggest to focus on the dinucleotide SSRs localised in UTR (more heterozygous and polymorphic) to increase the efficiency of mapping loci and then to reduce the cost of molecular marker screening between the parents of a progeny. In addition to mapping ESTs via microsatellite loci for locating putative functions, the EST-SSR markers developed in this study are powerful for the study of genetic diversity of citrus.

\section{Authors' contributions}

FLL carried out molecular genetic studies, data analysis and drafted the manuscript. GC and TA participated to generate results on genotyping. JT and XA generated the EST data base and did the annotation. PW and MT, were in charge of the clementine EST analysis in the framework Genoscope project. PO and RM coordinated the Genoscope project and participated to the drafting of the manuscript.

\section{Acknowledgements}

We thank the Collectivite Territorial de Corse for funding this study.

\section{References}

I. Tautz D: Hypervariability of simple sequences as a general source of polymorphic DNA markers. Nucleic Acid Res 1989, | 7:6463-647|.
2. Lanaud C, Risterucci AM, Pieretti I, Falque M, Bouet A, Lagoda PJL: Isolation and characterization of microsatellites in Theobroma cacao L. Molecular Ecology 1999, 8:2 I4I-2I 52.

3. Billotte N, Risterucci AM, Barcelos E, Noyer JL, Amblard P, Baurens FC: Development, characterisation, and across-taxa utility of oil palm (Elaeis guineensis Jacq.) microsatellite markers. Genome 200I, 44:4I3-425.

4. Bon MC, Hurard C, Gaskin J, Risterucci AM: Polymorphic microsatellite markers in polyploid Lepidium draba L. ssp. Draba (Brassicaceae) and cross-species amplification in closely related taxa. Molecular Ecology Notes 2005, 5:68-70.

5. Risterucci AM, Duval MF, Rohde W, Billotte N: Isolation and Characterization of microsatellite loci from Psidium guajava $L$. Molecular Ecology Notes 2005, 5:745-748.

6. Powell W, Morgante M, Andre C, Hanafey M, Vogel J, Tingey S, Rafalski JA: The comparison of RFLP, RAPD, AFLP and SSR (microsatellite) markers for germplasm analysis. Molecular Breeding 1996, 2:225-238.

7. Gupta PK, Varshney RK: The development and use of microsatellite markers for genetics and plant breeding with emphasis on bread wheat. Euphytica 2000, I I3:163-185.

8. Plieske J, Struss D: Microsatellite markers for genome analysis in Brassica. I. Development in Brassica napus and abundance in Brassicaceae species. Theor Appl Genet 200I, 102:689-694.

9. Cordeiro GM, Pan YB, Henry RJ: Sugarcane microsatellites for the assessment of genetic diversity in sugarcane germplasm. Plant Science 2003, 165:181-189.

10. Agrama HA, Tuinstra MR: Phylogenetic diversity and relationships among sorghum accessions using SSRs and RAPDs. African Journal of Biotechnology 2003, 2:334-340.

II. Kijas JMH, Thomas MR, Fowler JCS, Roose ML: Integration of trinucleotide microsatellites into a linkage map of citrus. Theor Appl Genet 1997, 94:70I-706.

12. Froelicher Y, Dambier D, Costantino G, Lotfy S, Didout C, Beaumont V, Brottier P, Risterucci A-M, Luro F, Ollitrault P: Characterization of microsatellite markers in Citrus reticulata Blanco. Molecular Ecology Note 2007.

13. Luro F, Rist D, Ollitrault $P$ : Evaluation of genetic relationships in Citrus genus by means of sequence tagged microsatellites. In Proceedings of the International Symposium on Molecular markers for characterizing genotypes and identifying cultivars in horticulture: 6-8 marsh 2000 Volume 546. Edited by: Doré C, Dosba F, Baril C. ISHS Acta Horticultarae; 200I:537-542.

14. Barkley NA, Roose ML, Krueger RR, Federici CT: Assessing genetic diversity and population structure in a citrus germplasm collection utilizing simple sequence repeat markers (SSRs). Theor Appl Genet 2006, I | 2:1519-153I.

15. Thiel T, Michalek W, Varshney RK, Graner A: Exploiting EST databases for the development and characterization of genederived SSR-markers in barley (Hordeum vulgare L.). Theor Appl Genet 2003, 106:4 I I-422.

16. Gao LF, Jing RL, Huo NX, Li Y, Li XP, Zhou RH, Chang XP, Tang JF, Ma $Z Y$, Jia JZ: One hundred and one new microsatellite loci derived from ESTs (EST-SSRs) in bread wheat. Theor Appl Genet 2004, 108:1392-1400.

17. La Rota M, Kantety RV, Yu JK, Sorrells ME: Nonrandom distribution and frequencies of genomic and EST-derived microsatellite markers in rice, wheat, and barley. BMC Genomics 2005, 6:23.

18. Forment J, Gadea J, Huerta L, Abizanda L, Agusti J, Alamar S, Alos E, Andres F, Arribas R, Beltran JP, Berbel A, Blazquez MA, Brumos J, Canas LA, Cercos M, Colmenero-Flores JM, Conesa A, Estables B, Gandia M, Garcia-Martinez JL, Gimeno J, Gisbert A, Gomez G, Gonzalez-Candelas L, Granell A, Guerri J, Lafuente MT, Madueno F, Marcos JF, Marques MC, Martinez F, Martinez-Godoy MA, Miralles S, Moreno P, Navarro L, Pallas V, Perez-Amador MA, Perez-Valle J, Pons C, Rodrigo I, Rodriguez PL, Royo C, Serrano R, Soler G, Tadeo F, Talon M, Terol J, Trenor M, Vaello L, Vicente O, Vidal Ch, Zacarias L, Conejero V: Development of a citrus genome-wide EST collection and cDNA microarray as resources for genomic studies. Plant Mol Biol 2005, 57:375-391.

19. Terol J, Conesa A, Colmenero JM, Cercos M, Tadeo FR, Agustí J, Alós E, Andres F, Soler G, Brumos J, Iglesias DJ, Götz S, Legaz F, Argout X, Courtois B, Ollitrault P, Dossat C, Wincker P, Morillon R, Talon M: Analysis of 13000 unique Citrus clusters associated with fruit 
quality, production and salinity tolerance. BMC Genomics 2007 8:31.

20. Cordeiro GM, Casu R, McIntyre CL, Manners JM, Henry RJ: Microsatellite markers from sugarcane (Saccahrum spp.) ESTs cross transferable to erianthus and sorghum. Plant Science 200I, 160: III5-1I23.

21. Scott KD, Eggler P, Seaton G, Rossetto M, Ablett EM, Lee LS, Henry $\mathrm{RJ}$ : Analysis of SSRs derived from grape ESTs. Theor Appl Genet 2000, 100:723-726.

22. Holton TA, Christopher JT, McClure L, Harker N, Henry RJ: Identification and mapping of polymorphic SSR markers from expressed gene sequences of barley and wheat. Mol Breed 2002, 9:63-71.

23. Chen C, Zhou P, Choi YA, Huang S, Gmitter FG: Mining and characterizing microsatellites from citrus ESTs. Theor Appl Genet 2006, I I 2: 1248-1257.

24. Ollitrault P, Luro F: Citrus. In Tropical plant breeding Edited by: Charrier A, Jacquot M, Hamon S, Nicolas D. Montpellier: CIRAD 2001:55-77.

25. Oliveira RP, Cristofani M, Vildoso CIA, Machado MA: Genetic linkage maps of 'Pêra' sweet orange and 'Cravo' mandarin with RAPD markers. Pesquisa Agropecuária Brasileira 2004, 39:159-165.

26. Ruiz C, Asins MJ: Comparison between Poncirus and Citrus genetic linkage maps. Theor Appl Genet 2003, 106:826-36.

27. Bernet GP, Margaix C, Jacas J, Carbonell EA, Asins MJ: Genetic analysis of citrus leafminer susceptibility. Theor Appl Genet 2005 I I 0:1393-400.

28. Weber CA, Moore GA, Deng Z, Gmitter FG: Mapping freeze tolerance quantitative trait loci in a Citrus grandis $\times$ Poncirus trifoliata FI pseudo-testcross using molecular markers. J Amer Soc Hort Sci 2003, I 28:508-5। 4.

29. Siviero A, Cristofani M, Machado MA: QTL mapping associated with rooting of stem cuttings from Citrus sunki $\times$ Poncirus trifoliate hybrids. Crop breeding and Applied Biotechnology 2003 3:83-88.

30. Siviero A, Cristofani M, Furtado EL, Garcia AAF, Coelho ASG, Machado MA: Identification of QTLs associated with citrus resistance to Phytophthora gummosis. Journal of applied genetics 2006, 47:23-28.

31. Lyon MT, Federic CT, Kacar Y, Chen C, O'Malley D, Chaparro JX Gmitter FG, Roose ML: SSR-Based Linkage Maps For Sweet Orange And Trifoliate Orange [abstract]. Plant \& Animal Genome XVth Conference, January I 3-I 7, 2007 Town \& Country Convention Center San Diego, CA.

32. Transcript reconstruction and variation analysis management system (StackPACK ${ }^{\mathrm{TM}}$ ) [http://www.egenetics.com/stack pack.html]

33. MIcroSAtellite identification tool (MISA) [http://pgrc.ipkgatersleben.de/misa]

34. Rozen S, Skaletsky H: Primer 3 on the WWW for general users and for biologist programmers. In Bioinformatics methods and protocols: methods in molecular biology Edited by: Krawetz S, Misener S. Totowa: Humana Press; 2000:365-386.

35. Berardini TZ, Mundodi S, Reiser L, Huala E, Garcia-Hernandez M, Zhang P, Mueller LA, Yoon J, Doyle A, Lander G, Moseyko N, Yoo D Xu I, Zoeckler B, Montoya M, Miller N, Weems D, Rhee SY: Functional Annotation of the Arabidopsis Genome Using Controlled Vocabularies. Plant Physiol 2004, I 35:745-755

36. Conesa A, Gotz S, Garcia-Gomez JM, Terol J, Talon M, Robles M Blast2GO: a universal tool for annotation, visualization and analysis in functional genomics research. Bioinformatics 2005 21:3674-3676.

37. Doyle JJ, Doyle JL: A rapid DNA isolation procedure for small quantities of fresh leaf tissue. Phytochem Bull 1987, 19:1 I-I5.

38. Chalhoub BA, Thibault S, Laucoou V, Rameau C, Höfte H, Cousin R: Silver staining and recovery of AFLP amplification products on large denaturing polyacrylamide gels. BioTechniques 1997 , 22:216-220.

39. Dice L: Measure of the amount of ecologic association between species. Ecology 1945, 26:297-302.

40. Saitou N, Nei M: The neighbor-joining method: A new method for reconstructing phylogenetic trees. Mol Biol Evol 1987 4:406-425.

4I. Kumpatla SP, Mukhopadhyay S: Mining and survey of simple sequence repeats in expressed sequence tags of dicotyledonous species. Genome 2005, 48:985-998.
42. Poncet V, Rondeau M, Tranchant C, Cayrel A, Hamon S, de Kochko A, Hamon P: SSR mining in coffee tree EST databases: potential use of EST-SSRs as markers for the Coffea genus. Mol Gen Genomics 2006, 276:436-449.

43. Varshney RK, Graner A, Sorrells ME: Genetic microsatellite markers in plants: features and applications. Trends Biotechnol 2005, 23:1.

44. Sharma PC, Grover A, Kahl G: Mining microsatellites in eukariotic genomes. Trends biotechnol 2007, 25: II.

45. Berube Y, Zhuang J, Rungis D, Ralph S, Bohlmann J, Ritland K: Characterization of EST-SSRs in lobolly pine and spruce. Tree Genetics and Genomes 2007, 3:25I-259.

46. Gao LF, Tang JF, Li HW, Jia JZ: Analysis of microsatellites in major crops assessed by computational and experimental approaches. Mol Breed 2003, I 2:245-26I.

47. Barrett HC, Rhodes AM: A numerical taxonomic study of affinity relationships in cultivated Citrus and its close relatives. Syst Bot 1976, I:105-136.

48. Scora RW: On the history and origin of Citrus. Bull Torr Bot Club 1975, 102:369-375.

49. Ollitrault P, Jacquemond C, Dubois C, Luro F: Citrus. In Genetic diversity of cultivated plants Edited by: Montpellier: CIRAD. Hamon P, Seguin M, Perrier X, Glaszmann X; 2003:193-197.

50. Herrero R, Asins MJ, Carbonell EA, Navarro L: Genetic diversity in the orange subfamily Aurantioideae. I. Intraspecifies and intragenus genetic variability. Theor Appl Genet 1996, 92:599-609.

5I. Nicolosi E, Deng ZN, Gentile A, La Malfa S, Continella G, Tribulato E: Citrus phylogeny and genetic origin of important species as investigated by molecular markers. Theor Appl Genet 2000, 100: II55-1166.

52. Federici CT, Fang DQ, Scora RW, Roose ML: Phylogenetic relationships within the genus Citrus (Rutaceae) and related genera as revealed by RFLP and RAPD analysis. Theor Appl Genet 1998, 94:812-822.

53. Gulsen O, Roose ML: Chloroplast and nuclear genome analysis of the parentage of lemons. I Amer Soc Hort Sci 200I, I 26:210-2| 5 .

54. Jarrell DC, Roose ML, Traugh SN, Kupper RS: A genetic map of Citrus based on the segregation of isozymes and RFLPs in an intergeneric cross. Theor Appl Genet 1992, 84:49-56.

55. Durham RE, Liou PC, Gmitter FG Jr, Moore GA: Linkage of restriction fragment length polymorphisms and isozymes in citrus. Theor Appl Genet 1992, 84:39-48.

56. Cai $\mathrm{Q}$, Guy $\mathrm{CL}$, Moore GA: Extension of the linkage map in citrus using random amplified polymorphic DNA (RAPD) markers and RFLP mapping of cold-acclimation-responsive loci. Theor Appl Genet 1994, 89:606-6|4.

57. Luro F, Lorieux M, Laigret F, Bové JM, Ollitrault P: Genetic mapping of an intergeneric Citrus hybrid using molecular markers. Fruits 1994, 49:404-408.

58. Moore GA, Tozlu I, Weber CA, Guy CL: Mapping quantitative trait loci for salt tolerance and cold tolerance in Citrus grandis (L.) Osb. $\times$ Poncirus trifoliata(L.) Raf. Hybridpopulations. Acta Horticulturae 2000, 535:37-45.

59. Chen C, Bowman KD, Choi Ya, Dang PM, Rao MN, Huang S, Soneji JR, McCollum TG, Gmitter FG: EST-SSR genetic maps for Citrus sinensis and Poncirus trifoliate. Tree Genetics \& Genomes 2008 , $4: 1-10$. 